\title{
Oxidative Stress Evaluation in Rats Anesthetized with Isoflurane or Sevoflurane
}

\author{
Flavia RUXANDA, Viorel MICLĂUŞ, Vasile RUS, Adrian GAL, Liviu OANA \\ Faculty of Veterinary Medicine, University of Agricultural Sciences and Veterinary Medicine Cluj- \\ Napoca, 3-5 Mănăștur Street, 400372, Romania \\ Corresponding author: vmiclaus@usamvcluj.ro
}

Bulletin UASVM Veterinary Medicine 72(1) / 2015,

Print ISSN 1843-5270; Electronic ISSN 1843-5378

DOI:10.15835/buasvmcn-vm: 10389

\begin{abstract}
Oxidative stress implies an imbalance between antioxidant production and reactive oxygen species generation. In this experimental study, we aimed to assess the effects of two inhalational anesthetics (isoflurane and sevoflurane) on the antioxidant enzymes, namely: superoxid dismutase and glutathione peroxidase. Our protocol included 40 Wistar female rats, divided into 8 groups (5 animals per group): IM, I1, I2, I3, SM, S1, S2 and S3. The groups were subdued to: oxygen alone (control groups IM and SM), isoflurane (I1, I2, I3) and sevoflurane anesthesia (S1, S2, S3), 3 times, for 2 hours long, every other day. The supplied oxygen was $11 \mathrm{O}_{2} / \mathrm{min}$ and the concentration of isoflurane and sevoflurane was 1 minimum alveolar concentration (1 MAC). We harvested blood samples from each group at different moments: IM, SM, I1, S1 - immediately, I2, S2 - 6 hours and I3, S3 - 24 hours after the treatment. We assessed superoxid dismutase and glutathion peroxidase in the red blood cells. Both anesthetics did not significantly change the SOD activity, while GPx was significantly decreased in groups I3, S3 $(\mathrm{p}<0.05)$ and S2 $(\mathrm{p}<0.01)$.
\end{abstract}

Keywords: glutation peroxidase, isoflurane, sevoflurane, superoxid dismutase.

\section{INTRODUCTION}

The inbalance between antioxidant production and reactive oxygen species generation characterizes the oxidative stress. There is little information about lipoperoxidation, antioxidant capacity and oxidative DNA damage in isoflurane or sevoflurane anesthetized patients, during surgical procedures (Salvadori, 2012).

\section{AIMS AND OBJECTIVES}

This study aimed to evaluate the effects of isoflurane and sevoflurane anesthesia on two antioxidant enzymes (superoxid dismutase and glutathione peroxidase) on rats undergoing repeated inhalation anesthesia.

\section{MATERIALS AND METHODS}

The Scientific Research Ethics Commitee of UASVM Cluj-Napoca approved the protocol of the study, which included 40 female Wistar rats. The animals were divided into 8 groups. Groups I1, I2, I3 were anesthetized with isoflurane, groups
S1, S2, S3 with sevoflurane and groups IM and SM were the control groups. The control groups were exposed to oxygen alone $\left(11 \mathrm{O}_{2} / \mathrm{min}-3\right.$ times for 2 hours long, every other day). The experimental groups were anesthetized 3 times, for 2 hours long, every other day. Blood samples were harvested from the retro-orbital venous sinus, in $2 \mathrm{ml} \mathrm{K}_{3}$ EDTA vacutainer tubes at different times: immediately (IM, SM, I1, S1), 6 hours (I2, S2) and 24 hours $(\mathrm{I} 3, \mathrm{~S} 3)$ after the anesthetic treatment.

Superoxid dismutase (SOD) and glutathion peroxidase (GPx) activities were assessed in the erythrocytes by a kinetic method described by Flohe and Otting (1984) and Flohe and Gunzler (1984), respectively. The reactives used for SOD determination were: Xanthine oxidase gr. III 25 UN (Germany) and Cytocrome c 100 mg (Germany) and for GPx: $\beta$ Nicotinamide adenine dinucleotide phosphate $25 \mathrm{mg}$ (Germany), L-glutathione reduced $1 \mathrm{~g}$ (Germany) and Glutathione Reductase $100 \mathrm{U}$ (Germany). We used a Jasco V-530 Spectrophotometer, with double beam that covers 
Tab. 1. Erythrocyte concentrations of antioxidant enzymes (mean values)

\begin{tabular}{ccccccccc}
\hline & \multicolumn{4}{c}{ Isoflurane } & \multicolumn{4}{c}{ Sevoflurane } \\
\hline Group & IM & I1 & I2 & I3 & SM & S1 & S2 & S3 \\
\hline SOD(U/g Hb) & 1171.36 & 728.57 & 1286.94 & 1117.82 & 1430.46 & 1296.08 & 895.42 & 762.75 \\
GPx (U/g Hb) & 69.22 & 48.65 & 56.38 & $38.34^{*}$ & 109.64 & 72.03 & $46.82^{* *}$ & $35.79 *$ \\
\hline
\end{tabular}

${ }^{*} \mathrm{p}<0.05$ and ${ }^{* *} \mathrm{p}<0.01$ compared to the control group values

wavelengths from 200 to $900 \mathrm{~nm}$. For the statistical analysis we used the GraphPad Software, where we applied the Student's t test.

\section{RESULTS AND DISCUSSION}

After isoflurane anesthesia, SOD activities in erythrocytes suffered unsignificant changes in all experimental groups, in comparison to the control group. GPx activities decreased after isoflurane anesthesia in group I3 $(\mathrm{p}<0.05)$. After sevoflurane anesthesia, erythrocytary SOD values suffered unsignificant variations in: S1, S2 and S3 groups. GPx values decreased after sevoflurane anesthesia in: S1 (unsignificant), S2 ( $<<0.01)$ and S3 ( $<<0.05)$ groups.

Turkan (2004) found that the erythrocyte SOD activities were lower after isoflurane anesthesia in the first hour and on the first day than those at preoperative values and also GPx values decreased $(p<0.01)$. Other studies showed that SOD and catalase activities decreased, while GPx activity increased after isoflurane anesthesia, but they were assessed from kidney tissue (Durak et al., 1999).

Naziroglu and Gunay (1999) said that the volatile anesthetics increase the oxidative stress by decreasing the antioxidant defense while, Durak et al. (1999) stated that the mechanism of oxidative stress induction takes place by generation of free radicals (e.g. superoxide anion).

\section{CONCLUSION}

Our results show that the inhalational anesthetics do not change the activity of SOD significantly. On the other hand, the GPx activity values are decreased significantly $(p<0.05) 24$ hours post-anesthesia after both isoflurane and sevoflurane anesthesia, and only sevoflurane decreased the GPx activity very significant $(p<0.01)$ in group S2. Thus, the inhalational anesthetics induce oxidative stress to a certain extent, by lowering the antioxidant defense.

Acknowledgements. This paper was published under the frame of European Social Fund, Human Resources Development Operational Programme 2007-2013, project no. POSDRU/159/ $1.5 / \mathrm{S} / 136893$

\section{REFERENCES}

1. Durak I, Ozturk HS, Dikmen B, Guven C, Cimen MY, Buyokkocak S, Kacmaz M, Avci A (1999). Isoflurane impairs antioxidant defence system in guinea pig kidney. Can J Anaesth 46:797-802.

2. Flohe L, Otting F (1984). Superoxide dismutase assay. In: Lester Packer(ed). Methods in Enzymology vol 105: Oxygen Radicals in Biological Systems, Academic Press Inc, 93.

3. Flohe L, Gunzler W (1984). Assays of glutathione peroxidase. In : Lester Packer(ed). Methods in Enzymology vol.105: Oxygen Radicals in Biological Systems, Academic Press Inc, 114-122.

4. Naziroglu M, Gunay C (1999). The levels of some antioxidant vitamins, glutathione peroxidase and lipoperoxidase during the anaesthesia of dogs. Cell Biochem Funct 17:207-212.

5. Salvadori D (2012). No oxidative Stress or Genotoxicity in Patients under Isoflurane or Propofol Anesthesia. Qscience Proceedings: vol. 2012, Environmental Mutagens in Human Populations 85. DOI: 10.5339/qproc.2012. mutagens.3.85

6. Turkan H, Bukan N, Sayal A, Aydin A, Bukan H (2004). Effects of Halothane, Englurane, and Isoflurane on Plasma and Erythrocyte Antioxidant Enzymes and Trace Elements. Biological Trace Element Research 102:105112. 